\title{
Sources of Risk and Related Effects in the Malaysian Construction Industry
}

\author{
Sim NeeTing ${ }^{(\bowtie)}$ and Beatrice Jarit \\ Department of Civil Engineering, Faculty of Engineering, \\ Universiti Malaysia Sarawak, 94300 Kota Samarahan, Sarawak, Malaysia \\ snting@unimas.my
}

\begin{abstract}
Construction projects nowadays have higher complexities, calling for increased awareness, assessment and management of the risks involved. Key construction risks need to be first identified, then assessed and methods on risk mitigation need to be mapped out to better managed the potential of undesirable events within projects. This study aims to compile Malaysian construction related risks and their relevant impacts on the construction project risk and its effects to the construction projects. It serves as a compilation database for Malaysian construction project, which will be used as future risk data. Data was collected by conducting structured questionnaire surveys and distributing it to professionals involved in the construction industry. Discussion herewith will emphasize on the findings related to project risks detected based on the sources of risk. The risks will be group under specific groups of risk and linked with the effects the said risks produced. This project correlates the sources and effects of construction risks in Malaysia. It is hopeful that through this research, a proper knowledge or risk retention centre can ultimately be created to aid future effective qualitative and quantitative risk analysis for all construction projects.
\end{abstract}

Keywords: Construction $\cdot$ Risks $\cdot$ Effects $\cdot$ Malaysia

\section{Introduction}

The construction sector has always been to an indispensable arm to the economic growth in Malaysia and represents an essential parts of the economy, creating welathy and providing better standard of living to its nation. This sector alone has contribute to $3.3 \%$ of GDP even in early 2000s and have persistently contribute between 3-6\% to the nation's economic activities. According to the statisitcs by Hirshman (2020), the industry has also engaged about 1.46 million workers between 2015-2019. Numbers of projects awarded as of June 2008 are 5,768 with a total value of RM 58955.65 million (Malbex, 2009) and CIDB stated an over 40 billions worth of projects were awarded in the year 2017. The civil engineering sub-sector grew 6.3\% (January-June 2007: 3.5\%) (MALBEX, 2009). However, with increasing numbers of projects taking off and nature of projects are now multidisciplinary, combining various sectors and involving higher complexity in terms of skills, technology and materials, it is safe to say that every project now carries higher risks of failure and involves more uncertainties and variations.

Risks are basically possibilities of some events that bring negative consequences to occur in a project environment. They are uncertainties that will bring adverse impact. 
Dear Prof/ AP/ Dr/ Sir and Madam,

Warm greetings from Department of Civil \& Environmental Engineering, Universiti Teknologi PETRONAS (UTP), Malaysia

First, on behalf of the organizing committee, we would like to thank you for the support in submitting papers to our conference. Also, we would like to congratulate you also on the paper acceptances.

As promised earlier that all accepted papers will be published to the SCOPUS indexed Lecture Notes in Civil Engineering (LNCE) by Springer, in this year 2020 itself. With that, we would like to update that based on the communication with Springer, this conference publication will be tentatively available by $28^{\text {th }}$ Dec 2020 .

We thank you for your patience and apologise for any inconvenience caused during this time of great uncertainty. We are confident that with all of your unwavering support, ESTCON and ICCOEE will be better, bigger and bolder! For more info or to contact us, please email to iccoee2020@utp.edu.my or visit to our website http://estcon.utp.edu.my/iccoee.

Conference Chair,

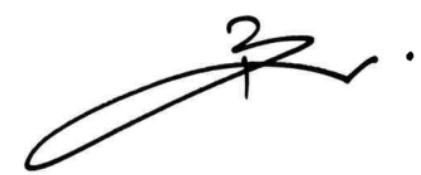

Assoc Prof Ir Dr Bashar S. Mohammed 


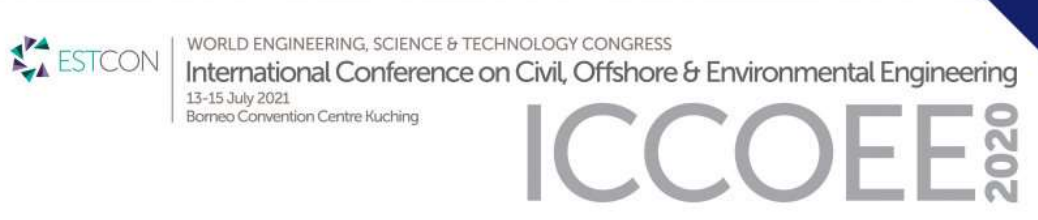

List of accepted papers from UNIMAS

\begin{tabular}{|l|l|}
\hline Corresponding Author & Paper ID \\
\hline Norazlina Bateni & 1570628922 \\
\hline Idawati Ismail & 1570635673 \\
\hline Yee Yong Lee & 1570635866 \\
\hline Sim Nee Ting & 1570637631 \\
\hline Ron Aldrino Chan & 1570637780 \\
\hline Mohammad Ibrahim Safawi bin Mohammad Zain & 1570646436 \\
\hline
\end{tabular}

